\title{
El desierto como representación del territorio septentrional de México ${ }^{1}$
}

\author{
The desert as territorial representation of Mexico's North
}

\author{
Enrique Rajchenberg S. ${ }^{2}$ \\ Catherine Héau-Lambert ${ }^{3}$
}

\section{RESUMEN}

El norte de México constituyó desde la época colonial un espacio de difícil colonización, tanto a causa de características físicas como de sus habitantes originarios. Por esa razón, las representaciones territoriales producidas en el centro del país respecto al septentrión fueron construcciones que lo referían como un desierto peligroso y productor de miedo. Para los estadounidenses quienes ambicionaban desde inicios del siglo XIX ese mismo espacio, sus habitantes eran la personificación de la degeneración racial. Este artículo analiza esta doble arquitectura de representaciones territoriales con la que se simbolizó al norte mexicano durante el siglo antepasado y que sigue reproduciéndose actualmente.

Palabras Clave: Norte de México. Frontera. Desierto. Representación territorial.

\section{ABSTRACT}

The northern region of Mexico presented a challenge for colonization since colonial times, both because of its physical features and for its indiegenous inhabitants. Is because of the former that the representations crafted in the central part of the country about the North always referred it as a dangerous, fearsome desert. For the US inhabitants, who wanted that same territory since the beginning of the XIX century, its inhabitants were the personified racial degeneration.

This article analyses this two-sided architecture of the territorial representations with which the North of Mexico was symbolized during the XIX century, and that is still reproduced nowadays.

Keywords: Mexico's North. Frontier-desert-terrritorial representation.

\footnotetext{
${ }^{1}$ El primer autor agradece el apoyo brindado por el Archivo Diplomático de la Secretaría de Relaciones Exteriores de la República Mexicana para realizar una parte de esta investigación en la Colección Nettie Lee Benson de la Universidad de Texas en Austin en 2008 y 2009.

${ }^{2}$ Universidad Nacional Autónoma de México.

${ }^{3}$ Escuela Nacional de Antropología e Historia-INAH.
} 
La noción de desierto simbolizó al norte mexicano en el imaginario de los habitantes del altiplano central durante la época colonial, el siglo XIX e incluso el XX. Ese vasto territorio que cubría parte de los estados actuales de Tamaulipas, Chihuahua, Durango, Coahuila, Nuevo León, Sonora y Baja California además de los 2 millones de $\mathrm{km}^{2}$ que fueron ganados por Estados Unidos tras la invasión de 1846-1848 era, para la mayor parte de los novohispanos y mexicanos ulteriormente, una porción del país de la que llegaban historias estremecedoras y de la que se dibujaban y escribían paisajes que no invitaban a recorrerlo. La noción de desierto era la que sintetizaba y representaba el extremo septentrional.

Al referirse al desierto, no se aludía a una descripción física del espacio, sino al vacío de significados que permitirían evocar este septentrión. Nadie hacía referencia a marcadores espaciales, vale decir, geosímbolos ${ }^{4}$ que implicaran una territorialización del espacio. Este vacío simbólico contrasta precisamente con la densidad simbólica del altiplano central. En esos confines, nada permitía recrear un sentimiento de pertenencia, nada parecía ser compartido. Si bien su densidad demográfica era muy baja, estaba lejos de estar deshabitado. ¿Por qué entonces se llamaba desierto? Esto es lo que intentaremos explicar en las siguientes páginas. ${ }^{5}$

No obstante nuestro objeto focal es México durante el siglo XIX, no es éste un caso excepcional en América Latina. Podemos afirmar que todos los países del subcontinente de vastas extensiones territoriales poseen "su" desierto. Argentina denominó toda la extensión al sur y al oeste de la provincia de Buenos Aires, vale decir, la Patagonia, desierto y, por ello, la eliminación de la población nativa en el último tercio del XIX fue denominada "campaña al desierto". En Brasil, hace no muchos años, la clase política brasileña se refirió al vacío amazónico. (BARTOLOMÉ, 2006, p. 294). El río Bio Bio en Chile delimitó para los españoles y para los criollos la frontera con el desierto, etc. Estamos, por lo tanto, ante un fenómeno no exclusivo de México, sino de muchas mayores proporciones que corresponde indudablemente a modos de representación compartida. ${ }^{6}$

La diferencia más notable del desierto mexicano respecto a sus homólogos continentales es que colindaba con otras posesiones coloniales o con naciones de ambiciones expansionistas. En efecto, el norte de México era contiguo al asentamiento francés en Luisiana, al ruso en la costa californiana y, por supuesto, era incursionado por expediciones de comerciantes y militares estadounidenses que se adentraban en el territorio. Precisamente, dedicamos el último apartado de este artículo a las representaciones estigmatizadas que los estadounidenses forjaron respecto

\footnotetext{
4 “El geosímbolo es un marcador espacial, un signo en el espacio que refleja y forja una identidad [...]. Los geosímbolos marcan el territorio con símbolos que arraigan las iconologías en los espacios-lugares. delimitan el territorio, lo animan, le confieren sentido y lo estructuran" (BONNEMAISON, 2000, p. 55).

${ }^{5}$ Retomamos en este texto algunos de los resultados de la investigación que fueron publicados en Rajchenberg y HéauLambert (2005a, 2005b, 2007, 2008a, 2008b, 2009).

${ }^{6}$ Un análisis comparativo de la noción de desierto en España y en la América colonial en Herzog (2007).
} 
a los colonizadores del septentrión mexicano. De este modo, este territorio quedó atrapado en la encrucijada de dos construcciones identitarias.

Figura 1 - El Norte: la última frontera

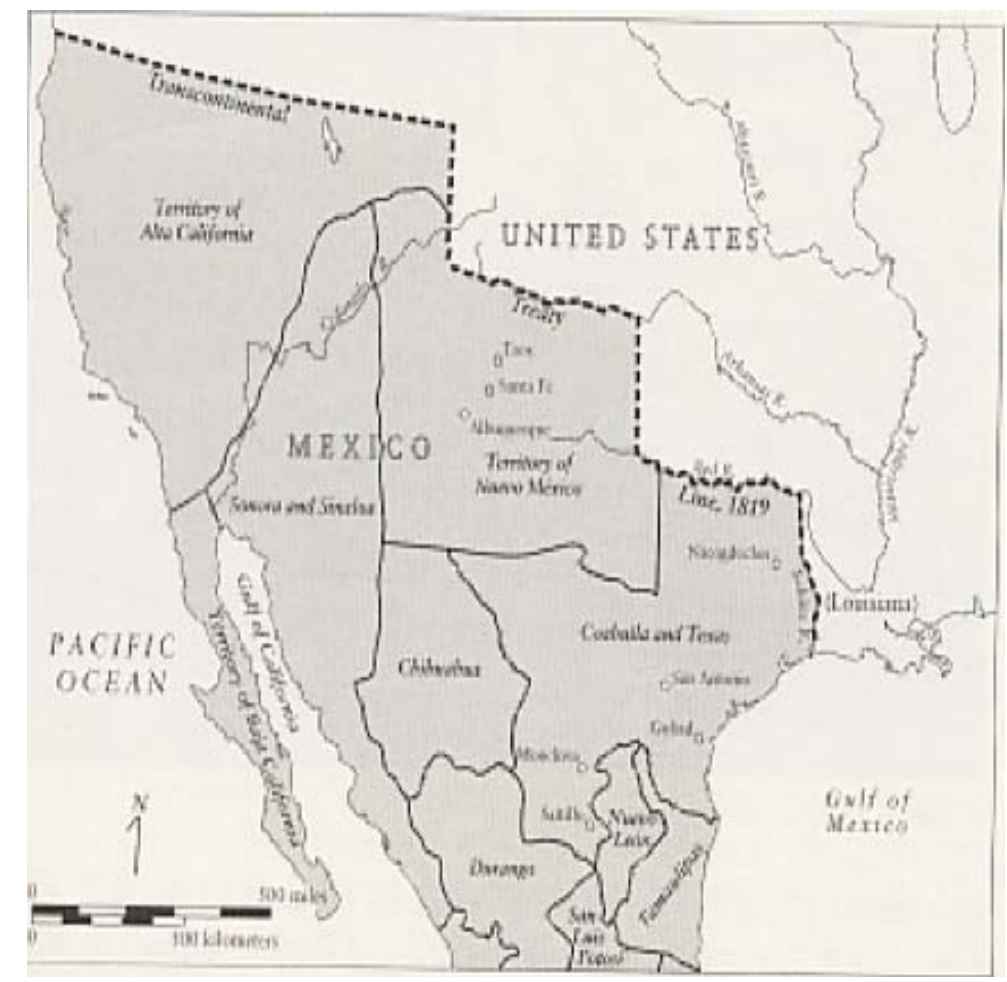

Fuente: Reséndez (2005, p. 19).

A diferencia del densamente poblado altiplano central y en contraste con su agricultura floreciente, los españoles se encontraron en el norte con un territorio más débil demográficamente. Si los indios del centro habían sido convertidos en indios tributarios de la Corona tras la conquista, también llamados "indios de paz" para contrastarlos con los indios belicosos, o sea los "indios de guerra", ${ }^{7}$ en el norte este mecanismo colonial estaba vedado porque las formas de organización prehispánica habían sido totalmente distintas.

\footnotetext{
${ }^{7}$ Una tercera categoría aparece mencionada, los "indios de media paz", que eran los que eran "reducidos al trabajo forzado en establecimientos agrícolas y mineros y eran también los que se defendían y ofendían el resto del tiempo" (GIUDICELLI, 2009, p. 56-57).
} 
El imaginario social novohispano distinguía claramente entre los indios pacíficos, es decir sedentarios, útiles para los trabajos agrícolas y mineros, y los indios vagos o nómadas renuentes a todo asentamiento y trabajo fijo que poblaban el norte de Nueva España. La única excepción fueron unas tribus ya sedentarias asentadas arriba del Río Grande, entre Albuquerque y Taos, que los españoles denominaron entonces indios $P u e b l o^{8}$ y que respaldaron la creación de asentamientos españoles en los últimos territorios del famoso Camino de Tierra Adentro, única ruta comercial que vinculará el noroeste (Nuevo México, Chihuahua y Durango) con el centro del país, mientras que el noreste (Coahuila y Tejas) se surtían en Saltillo y recurría mucho al transporte marítimo por el Golfo de México (Galveston, Tampico y Veracruz). Durante la Colonia, estas comunidades de colonizadores hispanos e indios asentados, fueron abastecidas desde el altiplano mexicano y fungieron como frontera entre novohispanos y naciones indias.

En el norte, no había imperios, ni jerarquías dinásticas, tampoco ciudades majestuosas como Tenochtitlan que había asombrado a Hernán Cortés. Tampoco había indios agricultores de tiempo completo, sino poblaciones que recorrían a lo largo del año distancias considerables en busca de recursos que encontraban en diferentes sitios según la estación. En estas circunstancias, era evidentemente más fácil desplazarse en pequeños grupos de medio centenar de personas, o incluso menos, que hacerlo en enormes contingentes. Sólo en circunstancias excepcionales se agrupaban en grandes conglomerados, como en el caso de las guerras, para regresar luego de la contingencia a las dimensiones habituales.

En comunidades pequeñas, el vértice no puede estar muy alejado de la base y por ello los jefes se confundían prácticamente con el resto de los miembros, por una parte, y, por otra, eran frecuentemente removidos.

El avance de los españoles fue tortuoso en esta región. No sólo se toparon con la hostilidad de los indígenas, sino también con la imposibilidad de tejer una estructura de poder que se ganara la complicidad de los gobernantes indios como lo habían hecho en el centro de México. Un acuerdo de paz con uno de ellos era tan efímero como la permanencia del mismo en el cargo. Menos plausible aún era la posibilidad de contar con aquellos indios como reserva de mano de obra.

Para controlar los territorios poblados de indios nómadas, el Virreinato recurrió a los frailes jesuitas y franciscanos encargados de fundar misiones, una de las instituciones de la conquista del norte, que intentaron reagrupar y alimentar a los nómadas, apoyados a veces por destacamentos militares. Estas misiones facilitaron la migración de rancheros novohispanos, indios, mestizos y españoles, mayoritariamente en la región del Río Grande, llamada Nuevo México, pero igualmente en el septentrión Oeste, llamado California y en menor medida en los territorios del Este, llamados Tejas, donde el poblamiento se hizo en torno a San Antonio y la

\footnotetext{
${ }^{8}$ Protagonistas de una gran rebelión en 1680.
} 
Bahía del Espíritu Santo (Goliad), encargados de contener los avances de los aventureroscolonizadores anglos y franceses que llegaban desde Luisiana.

Si bien una parte de los territorios explorados, como Zacatecas y Chihuahua, contaba con extraordinarias riquezas minerales, en otros parecía no haber nada de interés desde el punto de vista mercantilista de la Corona y de la insaciable codicia de los conquistadores.

Por estas razones, la presencia española en el norte fue muy lenta y desigual. Las líneas de avanzada eran tanto las misiones como los presidios, es decir, fortificaciones militares ubicadas a cierta distancia unas de otras, de manera que repelieran tanto las incursiones de los indígenas como las de los extranjeros en el oriente, o sea en Texas. A medida que se afianzaba el control del territorio, la línea de presidios se recorría hacia el norte. La eficacia de la estrategia de ocupación fue azarosa durante el siglo XVII y parte del XVIII, tanto porque los envíos de dinero de la Corona para el sostén de los presidios eran irregulares como por la corrupción de los oficiales que acaparaban para uso personal parte del dinero remitido.

Al occidente, la costa de la Alta California albergaba a varias misiones que se habían mantenido a pesar de los avatares económicos; en el norte central, una suerte de península colonizadora penetraba en el actual estado de Nuevo México cuyo punto culminante eran Santa Fe y luego Taos. Por último, al oriente, el inmenso Texas con una población reducida de novohispanos compuesta por militares, algunos comerciantes y agricultores avecindados en las cercanías de los presidios. Aunque la precariedad acompañaba la vida de estos habitantes, lo cierto es que gozaban, gracias a la distancia, de una importante autonomía respecto a la capital del virreinato y a las disposiciones reales de prohibición de comerciar directamente con el extranjero. Los californianos lo hacían con los rusos, con barcos peruanos e ingleses que llegaban a sus costas y los residentes de Santa Fe empezaron a hacerlo a principios del XIX con los anglos que venían desde Saint Louis, Missouri. Los habitantes de Nuevo México lamentaban públicamente las interdicciones, aunque hacían negocios con los compradores de pieles de Estados Unidos ya que las mercancías remitidas desde la ciudad de México duplicaban su valor por efecto de los altos costos del transporte.

La lejanía tenía incluso otras consecuencias que no dejó de registrar Pedro Baptista Pino, el diputado a las Cortes de Cádiz, en un documento que presentó a inicios del siglo XIX. A sus 50 años de edad, decía, no había visto ni un solo obispo en su vida sino hasta llegar a Cádiz. El último jerarca eclesiástico que había visitado la comarca lo había hecho en 1760. Las 400 leguas, añadió, que separaban Nuevo México de Durango, sede del obispado, favorecían que muchas parejas vivieran "en el pecado" (PINO, 1812).

Entre la costa de California y Santa Fe en Nuevo México, había una tierra no colonizada ni explorada. Lo mismo sucedía entre este último punto y San Antonio de Béjar en Texas. La cartografía expresa idóneamente la cuestión. En un mapa de 1828, su autor apuntó respecto al 
occidente californiano "Se supone que estas montañas se estienden ${ }^{9}$ más al Norte de lo que se exhibe aqui; mas no existe dato alguno con que poderlas trazar con precisión". ${ }^{10}$ De igual manera, en otra representación cartográfica, se explicita en referencia al mismo lugar: "A 4 y 5000 pies de altura sobre el nivel del mar, rodeado de altas montañas principalmente habitadas por tribus salvajes que no han sido vistas o descritas por ningún viajero". ${ }^{11}$

Pero con la llegada de los Borbones al trono español, la geopolítica del norte de la Nueva España se transformó. En efecto, las reformas implementadas en el último cuarto del siglo XVIII por la Corona en América, las llamadas Reformas borbónicas, promovieron la expulsión de los jesuitas de la Nueva España lo que provocó el abandono de las misiones del norte y el debilitamiento del control político sobre los territorios norteños.

No obstante, a partir de la administración borbónica y como respuesta a la amenaza de expansión francesa e inglesa, Madrid envió varios comisionados a realizar expediciones en el norte con el objeto de informar al rey del estado que guardaban las fronteras. Se trataba de vigorizar el sistema de presidios sobre los cuales pesó un diagnóstico nada halagüeño por parte de los comisionados. Los presidios que colindaban con Luisiana fueron reorganizados por el temor de que los estadounidenses, ya propietarios de esa enorme porción de América del Norte, terminaran por anexarse también a Texas, algo que acontecerá medio siglo más tarde. Pero igualmente el interés fue desigual: el extremo norte interesó poco dado que hubo una tregua entre los grupos apaches y el gobierno virreinal entre 1790 y 1810: "Los escasos recursos de la Corona eran necesitados en otras partes del imperio y no debían ser gastados en un área que reportaba tan pocas utilidades" (WEBER, 1986, p. 240). De todas maneras, la guerra de independencia iniciada pocos años después, echó por tierra los proyectos borbónicos. A partir de 1810 , los recursos monetarios dejaron de usarse para fortalecer las fronteras septentrionales del imperio español en América y se canalizaron prioritariamente en el combate a la insurgencia independentista.

A partir del advenimiento de la nación mexicana, como epílogo de la guerra de independencia de 1810-1821 y la interrupción del comercio en el Camino de Tierra Adentro debido a la inseguridad y los enfrentamientos militares, así como la expulsión de los españoles en 1827, las misiones franciscanas quedaron muy debilitadas. La novel república mexicana pretendía mantener el control sobre el territorio mediante representantes administrativos y destacamentos militares, sin darse cuenta que el desmantelamiento del abasto desde el altiplano mexicano hacia los territorios septentrionales, obligaba a los colonos a buscar nuevas rutas comerciales que, inevitablemente, se establecieron con los territorios ocupados por los angloamericanos, ávidos de

\footnotetext{
${ }^{9}$ Hemos conservado la grafía original de los documentos históricos.

${ }^{10}$ Mapa de los Estados Unidos de Méjico, según lo organizado y definido por las varias actas del Congreso de dicha Republica. White, Gallaher, White, 1828.

${ }^{11}$ Mapa de los Estados Unidos de Méjico según lo organizado y definido por las varias actas del Congreso de dicha República y construido por las mejores autoridades. J. Disturnell, Nueva York, 1850.
} 
extender sus redes comerciales y territoriales. Se establecieron entonces fuertes relaciones mercantiles y la circulación de mercancías se acompañó de una importante migración desde Illinois, Missouri, Mississippi y Luisiana ${ }^{12}$. En 1821 se podían contar 28000 residentes hispanos en Nuevo México, mientras que sólo el $10 \%$ de la población de Tejas era hispana ${ }^{13}$. Los pobladores hispanos quedaron atrapados en la encrucijada de fundar una nueva identidad ${ }^{14}$ articulada en torno a su fe católica, su lengua y su origen étnico pero adaptada a los requerimientos cotidianos de una supervivencia económica basada en una agricultura cambiante y vínculos mercantiles muy fuertes con sus vecinos anglos. ${ }^{15}$ En palabras de Andrés Reséndez:

Two forces conditioned the identity choices of frontier residents in certain fundamental ways. The workings of the Mexican state and American markets collided at the frontier, often pulling in opposite directions, and thus forced the frontier population to confront a remarkably consistent set of identity choices and tensions (RESÉNDEZ, 2005, p. 4).

Como ya fue dicho en este trabajo, el abandono material, espiritual e ideológico del septentrión por parte de los habitantes - de la Nueva España y luego de la Republica Mexicanaradicados en el centro del país, tanto en tiempos del Virreinato como bajo la república, desvinculaba a los colonizadores hispanos de sus orígenes para reorientarlos hacia sus nuevos vecinos en una alianza absolutamente necesaria ante los embates de los ataques indios y la escasez de mercancías. En efecto, el avance hacia el Oeste de los colonizadores anglos, es decir, cruzando el Mississippi, empujaba a los indios de las planicies centrales (kiowas, comanches, wichitas, apaches, lipanes, gilas, zuñis, hopis, navajos) hacia el sur, es decir, en territorios reivindicados por los mexicanos quienes se sintieron amenazados, invadidos y encerrados por tribus indias, genéricamente llamadas Apaches o Comanches por los periódicos del centro de México. Éstos resaltaban su salvajismo y crueldad ya que los territorios mexicanos donde estos indios desplazados buscaron refugio, se hallaban desprovistos de bisontes por lo cual tuvieron que alimentarse con el ganado y las cosechas de los rancheros (mestizos e indios Pueblo). Estos asaltos eran alentados y favorecidos por la venta de armas y alcohol por parte de los anglos que se sirvieron de los indios para debilitar las colonizaciones hispanas. Los mexicanos hicieron entonces alianza con los colonos anglos para defender la región. Se reforzó de esta manera el

\footnotetext{
${ }^{12}$ La frontera norte de México conoció un significativo crecimiento económico a partir de entonces, principalmente impulsado por la ruta comercial que, partiendo de Saint Louis, arribaba a Santa Fe con cientos de carretas de mercancías (RESÉNDEZ, 2005, p. 93; DEL RÍO, 2011).

${ }^{13}$ Los habitants mexicanos de Texas sumaban alrededor de 2500 a 3000 individuos (CLARK, 2002, p. 5).

14 "The frontier society was caught in the middle, torn between the pull of institutions, patronage, orders, and rituals coming from the South and profits flowing from the North." (RESÉNDEZ, 2005, p. 123)

${ }^{15}$ Según Reséndez (2005, p. 106) los primeros productos americanos más solicitados fueron las medicinas (así como las consultas con los médicos anglos) y el alcohol.
} 
proceso de asimilación de la frontera norte hispana con los territorios sureños de la Unión Americana, particularmente Texas.

Esta fue la situación heredada por México al alcanzar la independencia: un territorio prácticamente desconocido para la mayoría de los habitantes del centro desde donde se pensaba gobernar 4 millones de $\mathrm{km}^{2}$ y al que se arribaba a sus confines septentrionales tras varios meses de un viaje extenuante. Desde los primeros tiempos independientes, los legisladores lanzaron encendidos discursos acerca de la necesidad de ocuparse del norte, al que llegaban a describir como un "paraíso" y, para ello, de colonizarlo sea con mexicanos, sea con extranjeros de países decididamente católicos, porque incluso en estas circunstancias de emergencia demográfica no se trataba de conceder la tolerancia religiosa. Era evidente para aquel entonces que el avance de los anglos sobre Texas era creciente. Desde 1821, se había otorgado a Moses Austin una concesión de tierras en aquella provincia. Su hijo Stephen había heredado la posesión, poblando el lugar con cientos de familias que venían del noreste estadounidense o bien de Alemania. La política colonizadora lanzada por el gobierno mexicano fracasó y la coyuntura política no favoreció en lo absoluto la dedicación a una remota parte del país. En 1836, Texas se escindía de México y en 1848 quedaba anexada a Estados Unidos junto con todo el lejano norte mexicano.

\section{Un paisaje del miedo}

La lejanía, la falta de abundantes tesoros de oro y plata y poblaciones indígenas indómitas desincentivaron a los españoles a adentrarse en el norte. Hernán Cortés tuvo que inventar fabulosas leyendas para animar a sus soldados a proseguir el camino. Se difundió el maravilloso mito de una ciudad cuyas fachadas estaban cubiertas por piedras preciosas y cuyos pobladores traían extraordinarios cinturones de oro:

Hernán Cortés y su gente reprodujeron diversas leyendas medievales entre las cuales se encontraba la imagen seductora del mito sobre California: isla poblada por espléndidas amazonas comandadas por Calafia. California expresaba la magnificación del deseo de los ávidos soldados, quienes la imaginaron como un espacio paradisíaco, abundante en bellas mujeres, oro y perlas" (VALENZUELA ARCE, 2000, p. 11).

El desengaño sobrevino rápidamente y la fantasía cedió el lugar a las no menos fantasiosas aunque terribles historias del norte. 
Los indios en nada eran comparables a los sometidos en primera instancia a partir de 1519. No tenían organización estatal, no eran pueblos agrícolas y, por lo tanto, no eran sedentarios: "En América se ha verificado el axioma de Voltaire de que los pueblos ó tribus nomades resisten por mas tiempo al poder y encantos de la civilizacion, que los que son labradores ó pastores" (ZÚÑIGA, 1835, p. 4).

Tampoco habían edificado grandiosas ciudades. En suma, adolecían de todo lo que, desde la perspectiva occidental, configura un orden civilizatorio. Eran, en una palabra, bárbaros; eran los bárbaros del desierto. Acerca de ellos podían germinar en el imaginario colectivo los relatos más espeluznantes, como el del canibalismo, que contenían escenas de seres humanos cocinados lentamente y a quienes se les comía poco a poco hasta dejar el esqueleto. Aunque ésta leyenda provenía de los siglos XVI y XVII, se repetiría en innumerables ocasiones durante los siguientes siglos.

Hacia mediados de XVI, Francisco Vázquez de Coronado partió a la conquista de las abundantes tierras norteñas. Su carta al rey revela una terrible decepción después de la búsqueda afanosa de la legendaria Cibola donde "las fachadas de las casas principales estaban cubiertas de turquesas": "La tierra es tan fría, como á V.M. tengo escrito, que parece imposible poderse pasar el invierno en ella, porque no hay leña ni ropa con que se puedan abrigar los hombres, sino cueros de que se visten los naturales, y algunas mantas de algodón, en poca cantidad".

Se alimentaron relatos terroríficos acerca de lo que sucedía en el norte: "Para disponer mejor y suavizar la carne de los infelices prisioneros condenados á servir de potaje en las orgías de los comanches, les frotan todo el cuerpo con cardos y pieles humedecidas hasta hacerles verter la sangre por todas partes" (RIVA PALACIO, 1987, p. 121, v. 7). El gobernador de Texas a finales del XVIII, Domingo Cabello y Robles, lamentó la pérdida de su cocinero, su secretario y su criado quienes habían huido convencidos que los indios se los comerían. El funcionario real, a pesar de todo, reconocía que habían procedido correctamente "porque este lugar es peor que Siberia y Laponia" (KESSELL, 2002, p. 357).

Los comisionados del rey no se toparon con "esos" indios, aun si comunicaron al rey su belicosidad. Sin embargo, esas leyendas arraigaron fuertemente y llegaron intactas al siglo XIX, cuando los enviados de la nueva república redactaron informes que detallaban las potencialidades de algunas partes del septentrión. A pesar de éstos, aquellas no dejaron de persistir. La fuerza que adquirieron estos relatos en el imaginario colectivo fue de tal envergadura que se repitieron a lo largo del tiempo otorgándoles un sello de veracidad que nadie desmentía. Pocos eran los que conocían el norte y éstos, cuando lo recorrían, lo veían a través del filtro de las leyendas transmitidas.

Cuando José María Sánchez, oficial que acompañó a la comisión encabezada por Mier y Terán en 1828, inició la travesía hacia el norte, escribió que los soldados "a cada paso se les 
figuraba que se les aparecían los indios y los asaban o se los comían vivos" (SÁNCHEZ, 1939, p. 10). Aunque el autor asegura no tener miedo, confiesa haber oído que los indios luego de haber hecho prisioneros a sus enemigos los "queman a fuego lento y en varios días, a otros les van cortando pedazos de carne poco a poco" (SÁNCHEZ, 1939, p. 34).

Tanto los libros escolares como la prensa y la literatura se hicieron eco de estas imágenes aterradoras que imposibilitaban la vida civilizada. A mediados del siglo XIX, el tema fue recurrentemente abordado en los periódicos. En una sección titulada "Bárbaros", El Monitor Republicano redactó la crónica de un ataque indígena a una población "habiendo principiado su bárbara acción por sacar los ojos y castrar á las víctimas” (16 de julio de 1852).

Para convencer de que los indios son equiparables a los animales o por lo menos que no llegan a ser plenamente humanos y que pertenecen al mundo salvaje , nunca se oye su voz: "Los gritos de sus habitantes se elevaban hasta el cielo pidiendo socorro; pero á esos gritos sólo respondía el alarido del salvaje" (El Universal, 3 de mayo de 1852).

El periódico El Siglo XIX publicó en 1850 poema titulado "El salvaje", acompañado por un dibujo en el que un indio con plumas y taparrabos está en actitud de proferir alaridos desde un peñasco. Los versos hablan de la "árida tierra" donde el indio, "cubierto el labio de rabiosa espuma”, secuestró y violó a "una joven bella/Vestida de albo y virginal ropaje”.

Los libros escolares reprodujeron la misma concepción. Un afamado autor consideraba que los límites norteños antes de la conquista eran "desiertos y establecimientos de tribus desconocidas" y que en el noreste habitaban "bárbaros chichimecos" (ROA BÁRCENA, 1986, p. 23). De manera similar, otro autor de manuales para estudiantes destacaba que Chihuahua poseía gran riqueza "aunque soporta la plaga de los bárbaros" y que Durango se había atrasado "debido á las incursiones de los bárbaros" (GONZÁLEZ CEVALLOS, 1866, p. 109). Otro más decía acerca de Chihuahua que sobre ese estado pesaba "la plaga de indios bárbaros, apaches y comanches" (RIVERA CAMBAS, 1874, p. 29).

Ahora bien, fue particularmente la literatura la que se refirió al espacio físico mismo del Septentrión. No fueron referencias directas a él, sino a través de la comparación del altiplano central con el extremo norte del país.

Los geosímbolos por excelencia son los volcanes cercanos a la capital del país o, incluso hacia el sureste, el Pico de Orizaba. Éstos definen el espacio que configura identitariamente a la nación porque remiten a una historia común. Basta mirar a los volcanes para que éstos nos relaten la historia de la nación. Equivale a leer un libro con una eficacia didáctica aun mayor. Así como los volcanes que circundan a la ciudad de México dan cuenta de la historia común, el altiplano se vuelve metonimia de toda la nación:

Un silencio de muerte reinaba 
En el suelo de Anahuac florido, $\mathrm{Y}$ tan solo de doliente gemido Se escuchaba de angustia y pesar.

El poema se refiere a la coyuntura previa al grito de Dolores en Guanajuato con el que inicia la insurgencia independentista de 1810 y resume al país en el valle de México. Así, concomitantemente, los aztecas se vuelven sinónimos de mexicanos: "A la lid se lanzaron valiente/ Del Azteca los indios llorosos".

En cambio, el desierto lo es porque no puede ser marcado. No hay nada en él que pueda evocar una tradición compartida entre los miembros de una familia nacional. Los efectos de contraste entre ambos espacios son explícitos en la poesía del siglo XIX:

\author{
El Popo y el Orizaba \\ El suelo oprimen con su mole inmensa \\ Y están envuelos entre nube densa \\ Sus cúspides de hielos y de lava. \\ Líneas más abajo, el poema dice: \\ En el desierto grave y silencioso \\ Entre sus melancólicas palmeras \\ Se deslizan las víboras ligeras \\ O estánse quietas en feliz reposo.
}

El símbolo más usual del desierto es el cactus al que se le confiere el sentido del espacio vacío, siempre rodeado de las víboras que indican peligro de muerte junto con las aves de carroña. Al referirse al altiplano, José María Tornel describía al colibrí y a las flores que lo alimentan y completaba la imagen con los colores del pájaro. Decía que la providencia lo ha vestido de "púrpura y oro" para hacerlo vivir "en la estación del amor y los placeres". El norte es tierra agresiva:

\author{
La árida tierra apenas se divisa \\ cubierta en parte por la yerba inculta \\ y aves nocturnas extendiendo el vuelo \\ mudas recorren el fatal camino. (Villalobos, \\ 1850).
}

Respecto a otras partes del norte, aunque con menos lirismo, los libros de las escuelas no despertaban mucho entusiasmo a los estudiantes con ciertas apreciaciones sobre el territorio: 
"Baja California. El aspecto de la península es desagradable; tiene quebrado el terreno, lleno de arenales y pedregoso, falto de agua, y en muchos lugares se presenta inhabitable; también está expuesto á recios huracanes, y las lluvias son tan escasas en la parte del Sur, que hay años en que no cae un solo aguacero" (RIVERA CAMBAS, 1874, p. 29).

La mitad del siglo XIX, coyuntura a la que ya nos hemos referido, vuelve a ser un ángulo analítico privilegiado. La presencia de indígenas en los estados del norte causa un verdadero terror en las elites ilustradas. La prensa emite entonces gritos de alarma. Lo que está en peligro es la nación misma, es decir, el centro del país. La civilización está cercada y potencialmente achicada. Zacatecas que ya se podía considerar centro del país, volvía a convertirse en norte bárbaro:

La nación en manos de los indígenas quedaría empobrecida, sería un campo muy dilatado con muy pocos habitantes, sería un desierto. No sería nación en verdad; porque los indígenas no tienen capacidad para organizar un gobierno, para crear un cuerpo de legisladores, ni para formar tribunales (El Monitor Republicano, 21 abril 1850).

Se evidencia así la homología entre dominio indígena y desierto. Toda la nación se volvería septentrión y se sucumbiría en el descrédito mundial ante la incapacidad de resguardar la causa de "la civilización y del cristianismo" (IZQUIERDO, 1945, p. 419).

La frontera interna que, desde los primeros tiempos de la conquista, los españoles habían tratado de correr hacia el norte, desciende hacia el sur: se trata del desplazamiento de "la república ilustrada" a los límites de Guadalajara y Guanajuato, pronostica un periodista. En una nota que utiliza un lenguaje colonial, se destaca "grave é inminente es el peligro que amenaza á las razas blancas de la nueva España, pues los indios bárbaros han tenido la osadía de penetrar hasta Zacatecas" (El Monitor Republicano, 22 jul. 1852).

El septentrión, al ser imaginado como desértico y salvaje, constituía un país diferente a México.Cuando José María Sánchez, el oficial de la primera expedición enviada al norte por la recién creada república, cruzó el río Bravo y se encontraba a $100 \mathrm{~km}$ de Laredo, hoy ciudad fronteriza con Estados Unidos, sintió una curiosa emoción: “Al contemplar que para mí desaparecían los terrenos montuosos donde vi la luz primera, una feroz melancolía se apoderó de mi alma y volví el rostro a México para dar un adiós tal vez a las personas que allá quedaban y merecían mis afectos y ternura" (SÁNCHEZ, 1939, p. 15). Era como si México, su país, quedaba atrás e ingresara a otro. 
Esta desafección por el norte se repitió efectivamente en otros que escribieron memorias de su viaje al norte. Manuel Payno, el autor de la famosa novela Bandidos de Río Frío, recorrió varias poblaciones septentrionales a inicios de los años cuarenta del XIX. Aunque celebra a los "admirables hombres del desierto" y a sus hermosas mujeres al igual que se congratula porque el lugar no esté lleno de léperos, es decir indigentes, como en las grandes ciudades del altiplano, al realizar un balance de lo que conoció, parece mucho menos animado: "Decididamente estos son unos países sin recuerdo y sin porvenir" (PAYNO, 1999, p. 32).

\section{El frontierman y el American Southwest}

El concepto de frontera en el siglo XIX mexicano expresa tanto la línea de separación entre estados, como los inmensos territorios limítrofes pertenecientes a las diversas naciones indias, pero considerados como despoblados (denominados jurídicamente como baldíos), que se ofrecen como premios a los que se atreven y arriesgan para poblarlos. Estos territorios del septentrión mexicano heredados de la Nueva España se vuelven manzanas de la discordia o centros de disputa entre naciones. Por un lado, la Unión Americana en expansión demográfica muy rápida $^{16}$, ascenso económico y rancheros con ímpetu para apropiarse y cultivar grandes extensiones de tierras movidos por el mito de la Tierra prometida; y, por otro, la República mexicana desorganizada por las luchas internas e incapaz de poblar y controlar tan vastos territorios que gozaban de una imagen negativa en México. Los escasos pobladores mexicanos asentados en los territorios del norte se hallaban prácticamente abandonados a su suerte.

En 1824 la República abrió sus territorios a la colonización, luego en $1830^{17}$ ante el flujo permanente de migrantes anglos, vale decir, provenientes de Estados Unidos, el Congreso mexicano intentó preservar la integridad territorial decretando la cancelación de los contratos de colonización con gran pesar de los tejanos estrechamente vinculados a los negocios anglos. Los tejanos gozaban de cierta autonomía gracias al sistema político federalista. Pero cuando el gobierno mexicano optó por el establecimiento de un sistema centralista, que creó mucho disgusto en el lejano norte, los pobladores anglos decidieron utilizar ese hecho como mera justificación retórica de su secesión en 1836 de México, creando la República de Tejas (Lone Star

\footnotetext{
${ }^{16}$ México contaba en 1821 con 6200000 habitantes y esa cantidad se mantuvo a lo largo de varias décadas. Contrastantemente, Estados Unidos tenía 9600000 personas, pero esta cantidad se multiplicó, gracias a la inmigración a 17 millones en 1840, vale decir, tres veces más que la población mexicana (WEBER, 1982, p. 159).

${ }^{17}$ En 1830, José Francisco Ruíz, de San Antonio y uno de los pilares de la pequeña comunidad mexicana de Texas, hizo un alegato en favor de las grandes corrientes migratorias hacia ese territorio, mismas que el gobierno central intentaba restringir: 'I cannot help seeing advantages which to my way of thinking, would result,' he said, 'if we admitted honest, hard-working people, regardless of what country they come from even hell itself."' (WEBER, 1988, p. 105)
} 
Republic), anexada diez años más tarde por la Unión Americana. El Presidente de México, General Antonio López de Santa Anna, organizó una expedición punitiva para castigar a los tejanos traidores. Obtuvo una victoria al tomar el fuerte de El Alamo en primer término, para después ser vencido y hecho prisionero. Fue liberado a cambio del reconocimiento de la independencia de este territorio del noreste mexicano.

A partir de este belicoso episodio se inició entre los norteamericanos, un montaje míticoideológico en torno a la bravura de los defensores ${ }^{18}$ anglos y se justificó la división racista de la sociedad entre anglos blancos heroicos y no-anglos morenos, pérfidos y crueles. El enfrentamiento con los mexicanos se había vuelto un eficaz instrumento de propaganda política que justificaba, apoyaba y sostenía el avance colonizador. El principal protagonista de la colonización de Tejas, Stephen Austin, justificaba en estos términos la apropiación anglo del norte mexicano: "A war of barbarism and of despotic principles, waged by the mongrel SpanishIndian and Negro race, against civilization and the Anglo-American race." ${ }^{\prime 19}$ El historiador David Weber destaca cómo la batalla de El Alamo fue "romantizada" para atribuirle significaciones transcendentes al hecho mismo. Se trataría, dice Weber, de una metáfora del triunfo del protestantismo sobre el catolicismo, de la democracia sobre el despotismo, de una raza superior sobre un pueblo degenerado de sangre mezclada, de dios sobre el diablo (WEBER, 1988, p. 138-140).

La creación del mito de El Álamo antecedió por diez años la victoriosa guerra de invasión norteamericana en todo el norte desde Texas hasta California y fue respaldada por otro mito, el Destino Manifiesto en 1839 que pregonaba el inevitable avance de los norteamericanos sobre todo el continente, en cumplimiento de la teoría enunciada por Monroe en 1823, originalmente acuñada por John Quincy Adams, para rechazar toda intromisión europea, "América para los americanos", pero en el entendimiento de que los únicos americanos valiosos y civilizados eran los de raza blanca, como lo mencionará Austin en su carta -arriba citada- de 1836.

Sobre la doctrina Monroe y la batalla de El Álamo se elaboró entonces en 1894 el segundo mito fundacional de los Estados Unidos, el Frontierman que representa el siempre anhelado y utópico hombre nuevo forjado por su control de la naturaleza y su valentía y que, en el ámbito urbano, se llamó también self-made man. De esta manera, la conquista del Oeste americano se explica por características individuales, por sujetos excepcionales que fueron los nuevos padres fundadores de la nación americana. En el imaginario colectivo heroico norteamericano, los cuáqueros de la primera ola de migración hacia la tierra prometida americana, los primeros fundadores de la patria, son seguidos por esta segunda ola compuesta de tramperos y granjeros dispuestos a enfrentar todos los peligros (naturaleza, animales e indios) para acceder a la posesión de las tierras salvajes y desocupadas.

\footnotetext{
${ }^{18}$ El más famoso de ellos fue sin duda Davy Crockett, quien fue apresado junto con otra media docena de texanos , mismos que fueron ejecutados por órdenes de Santa Anna, a pesar de haberse rendido previamente (WEBER, 1988, p. 137)

19 David J. Weber (1988, p. 139). Es instructivo comparar el desprecio de los anglos hacia los mexicanos y su cultura, mientras que los tejanos mexicanos apreciaban a los migrantes anglos, como se relató previamente.
} 
El frontierman, pionero totalmente liberado de todo vínculo o apego comunitario o religioso, que sólo ve por su propia realización y enriquecimiento como destino individual manifiesto, remplaza al cuáquero religioso que veía y velaba por una comunidad eclesiástica. Para Turner, es el epítome de la joven América y símbolo de una democracia autóctona diferente a Europa. Mientras los descendientes de los Pilgrim Fathers se empeñaban en representar y trasponer a Inglaterra en tierras americanas, este segundo mito fundacional permite construir y asentar una nueva identidad norteamericana en ruptura con los usos y costumbres ingleses y europeos. A medida que el país se expande hacia el oeste, se va alejando, desprendiéndose y diferenciándose de Europa. A partir de la diferencia se puede existir autónomamente. Para los historiadores posteriores, este personaje inventado ${ }^{20}$ se ha vuelto el paradigma que explica la identidad americana. Las características del frontierman, que por metonimia representaría a todos los norteamericanos, son inventiveness, practicality, inquisitiveness, restlessness, optimism and individualism.

Estos calificativos o atributos del americano de raza blanca creados a partir de categorías dicotómicas positivo/negativo, no crearon un mito sino que son el resultado de un mito preexistente, es decir, una construcción ideológica mítica basada en la creencia y afirmación de una superioridad racial que estuvo estructurando el imaginario colectivo anglo-americano desde los inicios de la "colonización" de Texas, como se demostró en este trabajo. El racismo angloamericano se materializaba en el mantenimiento a ultranza de la esclavitud, incluso en contra de las leyes mexicanas, y se extendía a la población mexicana mestiza. No queda duda de que la frontera anglo-americana era una frontera excluyente y altamente valorizada, mientras que, por contraste, el "otro" era receptor de marcas fuertemente negativas.

En la primera mitad del siglo XIX, muchos liberales mexicanos idealizaban la República americana y deseaban asemejarse a ella, particularmente los habitantes del norte fronterizo. Concebían la frontera como inclusiva, es decir, multirracial, aunque no exenta de racismo, ${ }^{21}$ pero la gran ofensiva bélica de 1846-1848 trajo consigo otra dura realidad social: los mexicanos se volvieron extranjeros en sus tierras. Oficialmente se habían vuelto ciudadanos americanos, pero como bien lo dice Orwell, ante la fuerza pública e, incluso, el derecho, "unos son más iguales que otros". Así los anglo-americanos recurrieron a los tribunales o a la violencia para apropiarse de las propiedades mexicanas. Entre la escasa resistencia mexicana, sobresale la figura de Juan Cortina, (1824-1894), un bandolero para los americanos, un héroe mítico para los mexicanos. ${ }^{22}$ Juan Cortina, quien demostró gozar de las mismas cualidades del frontierman, sin embargo, por ser mexicano resultó un bandolero a los ojos de los norteamericanos. Sus hazañas nos ofrecen

\footnotetext{
${ }^{20}$ Se retoma aquí el concepto de invención en el sentido acuñado por Eric Hobsbawm y Terence Ranger (2002) en la introducción a su libro sobre las tradiciones inventadas.

${ }^{21}$ Una sociedad multirracial, por desgracia, no implica en los hechos que todos los ciudadanos tengan las mismas oportunidades sociales, aun cuando la ley supone la igualdad de derechos.

${ }_{22}$ Para muchos de los "desperately poor, politically disfranchised, and economically abused along the river, he was a savior straight from heaven, a high-stepping brush country caudillo who would restore their pride and dignity, abolish the evils of the anglo-american barristers" (THOMPSON, 1994, p. 7).
} 
otra visión de la colonización anglo-americana y las cualidades de unos resultan ser pecados en otros.

\section{Colofón: desierto e identidad}

La desertificación simbólica del norte implicó la debilidad o ausencia total de vínculos identitarios con aquel territorio. Los pocos hombres que se atrevieron durante la primera mitad del siglo XIX a aventurarse en él sintieron, además de miedo, una total desafección hacia el septentrión, a pesar de los encendidos discursos sobre la integridad nacional que lanzaban de tanto en tanto los políticos (BENSON, 1989, p. 277).

Pasaron más de 50 años desde aquella época cuando José Vasconcelos, probablemente el intelectual más prestigiado del siglo XX mexicano, atravesó el norte. Durante ese medio siglo, el espacio económico norteño había sido incorporado al mercado mundial. Largas líneas troncales del ferrocarril surcaban ya el septentrión y conectaban a la capital del país con los confines de México, así como a éstos con Estados Unidos. El norte se había vuelto a lo largo de los últimos decenios del XIX y, sobre todo, durante el primero del XX en la región de más rápido crecimiento. También para ese entonces los aguerridos indios del norte habían sido aniquilados, confinados en reservas y su último líder, Gerónimo, había fallecido en cautiverio. Los revolucionarios del norte habían desplazado al dictador Díaz del poder y habían ocupado la ciudad de México. En aquel tiempo, pues, Vasconcelos no obstante escribiría: "Quien haya recorrido la sierra de Puebla, la meseta de Oaxaca, ya no digo el Bajío y Jalisco, comprenderá en seguida la impresión del mexicano del interior cuando avanza hacia el norte. Todo es barbarie. Hay una extensa no man's land del espíritu, un desierto de las almas" (VASCONCELOS, 1982, p. 512).

Más cerca aún de nosotros, en el año 2005, el gobernador del estado de Chihuahua declaró, al inaugurar un festival cultural, que uno de los objetivos del evento era el de "cambiar la imagen de bárbaros del norte" que tienen los chihuahuenses. No sólo el mote permaneció, sino la representación territorial en su conjunto a lo largo del siglo XX. Al final de esa centuria, el norte pareció ratificar la añeja concepción que los habitantes del centro del país incubaron durante siglos. Los feminicidios de Ciudad Juárez y posteriormente los violentos enfrentamientos de la narcoguerra reiteran el escenario violento que el lector de la prensa capitalina del XIX estaba acostumbrado a leer aunque no se sintiera particularmente concernido por algo que acontecía muy lejos y a muchas horas de camino del centro del país, salvo cuando esa misma violencia se acercaba peligrosamente al centro del país.

Por su parte, para los anglos, el norte de México era una metonimia territorial de su vecino del sur. La herencia hispánica sobre sus habitantes era un pesado lastre que había que 
remover para convertirlo a idea y semejanza de lo que los colonizadores ingleses del siglo XVII habían realizado en la costa este de Estados Unidos.

En otro contexto histórico, por supuesto, el inicio de siglo XXI tiene semejanzas con aquel momento. La guerra del narco alcanza ya al centro del país o ha envuelto a todo el país en un escenario de extrema violencia. Se antoja concebir una suerte de revancha del norte. Este territorio, excluido y desdeñado de las definiciones identitarias durante tanto tiempo, ahora imprime al país su imagen. Sucede como si las fronteras, "geografías del peligro y de la obsesión" (NORDMAN, 1998, p. 56), se hubieran apoderado de todo el territorio. El Anáhuac, metonimia de México durante el XIX, deja de ser tierra de colibríes como decía el poema, para convertirse en una extensión del desierto simbólico del norte.

En cambio, paradójicamente, los indios septentrionales que hacían imposible la "vida civilizada" permanecieron: "Los indios están ahí para contradecir. Por casi 500 años los 'naturales' resisten a la dominación: a veces guerreando, otras remontándose en la sierra, y también dejándose incorporar al sistema dominante aunque sin renunciar a cultura y costumbres" (BARTRA, 2010).

\section{Hemerografia}

El Monitor Republicano, Ciudad de México.

El Universal, Ciudad de México.

El Siglo XIX, Ciudad de México.

\section{Referências}

BARTOLOMÉ, Miguel. Procesos interculturales: antropología política del pluralismo cultural en América Latina. México: Siglo XXI, 2006.

BARTRA, Armando. Occidente: tierra indómita. La Jornada del Campo, México, n. 35, 2010.

BENSON, Nettie Lee. Territorial integrity in mexican politics, 1821-1833. In: RODRÍGUEZ, Jaime E. (Comp.). The independence of Mexico and the creation of the new nation, Los Angeles: University of California, 1989. p. 275-307.

BONNEMAISON, Joel. La géographie culturelle. París: CTHS, 2000. 
CLARK, Carol Lea. Imagining Texas. El Paso: Western Press, 2002.

DEL RÍO, Ignacio. Mercados en asedio. México: UNAM, 2011.

GIUDICELLI, Christophe. Naciones de enemigos? la identificación de los indios rebeldes en la Nueva Vizcaya (Siglo XVII). In: BERNABEU, Salvador (Coord.). El gran norte mexicano: indios, misioneros y pobladores entre el mito y la historia. Sevilla, Consejo Superior de Investigaciones Científicas, 2009. p. 27-66. (Colección Universos Americanos, v. 3).

GONZÁLEZ CEVALLOS, Faustino. Geografia de niños. Guadalajara: Dionisio Rodríguez, 1866.

HERZOG, Tamar. Terres et déserts, société et sauvagerie. Annales: Histoire, Sciences Sociales, París, n. 3, p. 507-538, 2007.

HOBSBAWM, Eric; RANGER, Terence. La invención de la tradición. Barcelona: Crítica, 2002.

IZQUIERDO, Izquierdo; JOAQUÍN, José. Cuatro años en Durango luchando sin recursos contra los bárbaros (1848-1852). México: Memorias de la Academia Mexicana de la Historia, 1945. t. 4.

KESSELL, John L. Spain in the Southwest: a narrative history of colonial New Mexico, Arizona, Texas and California. Albuquerque: University of Oklahoma Press, 2002.

NORDMAN, Daniel. Frontières de France: de l'espace au territoire. París: Gallimard, 1998.

PAYNO, Manuel. Panorama de México. México: Conaculta, 1999.

PINO, Pedro Baptista. Exposición sucinta y sencilla de la provincia del Nuevo México. Cádiz: Imprenta del Estado Mayor General, 1812.

RAJCHENBERG, Enrique; HÉAU-LAMBERT, Catherine. El Septentrión mexicano entre el destino manifiesto y el imaginario territorial. Journal of Iberian and Latin American Studies, Australia, v. 11, n. 1, 2005a.

. . . . La frontera en la comunidad imaginada del siglo XIX. La frontera norte, Tijuana, v. 19, n. $38,2007$.

_._. . La identidad nacional: entre la patria y la nación: México, siglo XIX. Cultura y representaciones sociales, México, n. 4, 2008a.

. Las fronteras de la patria. Estudios Sociológicos, México, v. 23, n. 67, 2005b.

. Para una sociología histórica de los espacios periféricos de la nación en América Latina. Antípoda, Bogotá, n. 7, 2008 b.

. Wilderness vs desierto? representaciones del septentrión mexicano en el siglo XIX. Norteamérica, México, v. 4, n. 2, 2009.

RESÉNDEZ, Andrés. Changing national identities at the frontier. Cambridge: Cambridge University Press, 2005.

RIVA PALACIO, Vicente. México a través de los siglos. México: Cumbre, 1987.16. v. 
RIVERA CAMBAS, Manuel. Atlas y catecismo de geografia y estadística de la República Mexicana. México: Imprenta de Flores y Monsalve, 1874.

ROA BÁRCENA, José María. Catecismo elemental de la historia de México. México: Instituto Nacional de Bellas Artes, 1986.

SÁNCHEZ, José María. Viaje a Texas, 1828-1829. México: Colección Papeles Históricos Mexicanos, 1939.

THOMPSON, Jerry D. Juan Cortina and the Texas-Mexico frontier. El Paso: Texas Western Press, 1994.

VALENZUELA ARCE, José Manuel. Entre la magia y la historia. México: El Colegio de la Frontera Norte-Plaza y Valdés, 2000.

VASCONCELOS, José. La tormenta: memorias. México: Fondo de Cultura Económica, 1982. t. 1.

WEBER, David J. Myth and the history of the hispanic southwest. Albuquerque: University of New Mexico Press, 1988.

The mexican frontier, 1821-1846: the american southwest under Mexico. Albuquerque: University of New Mexico Press, 1982.

WEBER, Michael Frederick. Tierra incognita: the spanish cartography of the american southwest, 1540-1803. 1986. Tesis (Doctor of Philosophy in History) - The University of New Mexico, Albuquerque.

ZÚÑIGA, Ignacio. Rápida ojeada al estado de Sonora. Méjico: Impreso por Juan Ojeda, 1835.

Recebido em 0/01/2012

Aprovado em 15/06/2012 